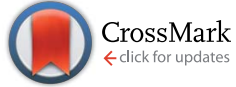

Cite this: RSC Adv., 2017, 7, 13668

Received 16th November 2016 Accepted 20th February 2017

DOI: 10.1039/c6ra26904d

rsc.li/rsc-advances

\section{Towards the development of an effective in vivo wound healing agent from Bacillus sp. derived biosurfactant using Catla catla fish fat $\uparrow$}

\begin{abstract}
Santanu Sana, ${ }^{a}$ Asit Mazumder, ${ }^{b}$ Sriparna Datta*c and Dipa Biswas ${ }^{d}$
The aim of the present study was to investigate the excisional wound healing activity of a biosurfactant isolated from Bacillus stratosphericus sp. A15 using Catla catla fish fat as economic substrate. The organism was screened on the basis of blood haemolytic activity, cell surface hydrophobicity, oil displacement test and its promising capacity of reducing surface tension (ST). The biosurfactant was identified as surfactin lipopeptide using IR, ${ }^{1} \mathrm{H}$ NMR and mass spectrometric analysis. Mass spectrometric data indicated the presence of amino acid sequence as Val/Asp/Val/Leu/Leu/GluOMe linked with $\beta$-hydroxy fatty acid moiety containing 14 carbons in normal, iso or anteiso forms. An ointment of the test biosurfactant enhanced the wound closure (97\%) in 10 days compared to the untreated control group (72\%) $(P<0.05)$. Histopathological study confirmed the healing effect of the test biosurfactant in terms of well developed keratinocyte, presence of hair follicles, vacuoles, higher number of intact cells in dermis layer and a thick epidermal layer. The biosurfactant also showed anti-oxidant and antibacterial activity against Staphylococcus aureus ATCC 25923 and Escherichia coli ATCC 8739 which established its' additional advantage in wound protection.
\end{abstract}

\section{Introduction}

Skin is the largest tissue of our body that protects from infections, ultraviolet irradiation, chemical and mechanical injury. Wound healing is a connective tissue regenerated complex procedure which involves the interaction of cells and extracellular matrix. ${ }^{1}$ The healing comprised of sequential and overlapped biological events involving inflammation, proliferation and migration of different cell types. ${ }^{2}$ After an injury, the wound should be repaired without delay with minimum pain, inflammation and discomfort excluding microbial infection. ${ }^{3}$ Antibiotics are generally used for treatment of infectious wounds. Unfortunately resistance development is of serious concern apart from side effects of these antibiotics. Hence the need for new wound healing agents with antimicrobial properties is on the rise.

Oxygen and nitrogen containing reactive species present at the wound site delay the healing process by lipid per-oxidation,

${ }^{a}$ Dept. of Chemical Technology, University of Calcutta, 92, A.P.C. Road, Kolkata - 700 oo9, India.E-mail: sanasantanu@gmail.com

${ }^{b}$ Dept. of Chemical Technology, University of Calcutta, 92, A.P.C. Road, Kolkata - 700 o09, India.E-mail: amaz234@gmail.com

'Dept. of Chemical Technology, University of Calcutta, 92, A.P.C. Road, Kolkata - 700 009, India. E-mail: sriparnadatta2014@gmail.com; Fax: +91-033-23519755; Tel: +919830695346; +91-33-2350-8386

${ }^{d}$ Dept. of Chemical Technology, University of Calcutta, 92, A.P.C. Road, Kolkata - 700 009, India. E-mail: dipa.b@yahoo.com

$\dagger$ Electronic supplementary information (ESI) available. See DOI: $10.1039 /$ c6ra26904d
DNA damage and free radical scavenger enzyme inactivation. Therefore new safe and effective wound healing agent with potential antioxidant activity has additional advantage to accelerate the healing process. ${ }^{4}$

Biosurfactants are microbiologically derived surface active agents containing both hydrophilic and hydrophobic substances ${ }^{5}$ which are preferred due to their biodegradable and environment friendly nature, biocompatibility, activity in extreme conditions of temperature, $\mathrm{pH}$ and salinity. ${ }^{6}$ Beside physicochemical properties, biosurfactant finds potential applications in pharmaceutical and cosmetic field for its antibacterial, antiviral and antifungal properties. ${ }^{7}$ The use of biosurfactant is restricted due to its production cost which can be reduced by using cheap substrate. We are pioneer in using waste fish fat as a cheap substrate, which is very much available in the local market of West Bengal. Till date only Deshpande M. and Daniels L. et al. ${ }^{8}$ have used animal fat to produce sophorolipid with Candida bombicola.

Accordingly, the present study is focused on the isolation, identification and pharmaceutical application in terms of wound healing activity of an efficient biosurfactant produced by a Bacillus sp. isolated from oil contaminated fertile soil.

\section{Materials and methods}

\subsection{Chemicals}

All the used reagents were of analytical grade. The 2,2-diphenyl1-picrylhydrazyl (DPPH), hydrogen peroxide $\left(\mathrm{H}_{2} \mathrm{O}_{2}\right)$, bovine 
serum albumin (BSA), trichloroacetic acid (TCA), ciprofloxacin (Albert David Ltd., India), D-(+)-glucosamine hydrochloride, acetyl acetone and Ehrlich's reagent were purchased from Sigma-Aldrich (India). Sodium hydroxide and hydrochloric acid were purchased from Merck (India). The fat of Catla catla fish, goat blood and waste frying oil were procured from local market. Bushnell-Haas (BH) media, peptone, beef extract and agar were from Hi-Media Laboratories Pvt. Ltd. (India).

\subsection{Culture medium components}

The medium used for isolation and biosurfactant production was $\mathrm{BH}$ media containing $\mathrm{KH}_{2} \mathrm{PO}_{4} 1 \mathrm{~g} \mathrm{l}^{-1}, \mathrm{~K}_{2} \mathrm{HPO}_{4} 1 \mathrm{~g} \mathrm{l}^{-1}$, $\mathrm{NH}_{4} \mathrm{NO}_{3} 1 \mathrm{~g} \mathrm{l}^{-1}, \mathrm{MgSO}_{4} 0.2 \mathrm{~g} \mathrm{l}^{-1}, \mathrm{CaCl}_{2} 0.2 \mathrm{~g} \mathrm{l}^{-1}, \mathrm{FeCl}_{3} 0.05 \mathrm{~g} \mathrm{l}^{-1}$ and autoclaved at $121^{\circ} \mathrm{C}$ for $15 \mathrm{~min}$. Enrichment medium was prepared by adding $20 \mathrm{~g} \mathrm{l}^{-1}$ Catla catla fish fat (FF) as sole carbon source in sterile $\mathrm{BH}$ medium. The bacterial culture was maintained in nutrient agar (NA) media and sub-cultured after every two weeks. The blood agar media containing $5 \%(\mathrm{v} / \mathrm{v})$ goat blood was prepared, following the method described by Qingmei L. et al. ${ }^{9}$

\subsection{Isolation, identification and screening of the biosurfactant producing bacteria}

Oil contaminated fertile soil samples were collected at late monsoon from Nadia district, West Bengal, India. The soil samples were inoculated in a $250 \mathrm{ml}$ Erlenmeyer flask containing $100 \mathrm{ml}$ enriched media and incubated at $35{ }^{\circ} \mathrm{C}$ in an orbital shaker incubator (ORBITEK-LJE, Scigenics Biotech Pvt. Ltd., Chennai, India) at $125 \mathrm{rpm}$ for 7 days. Single colony was isolated using serial dilution (up to $10^{-6}$ times) in sterile $0.85 \%$ saline solution, and finally streaked in NA plates. After confirming the purity of the isolated strain through Gram staining and examining its morphological, cultural, biochemical and physiological characteristics it was finally confirmed by $16 \mathrm{~S}$ rRNA gene sequence analysis (IMTECH, Chandigarh, India) and the sequence was submitted to NCBI/GenBank.

Haemolytic assay ${ }^{10}$ and oil displacement test ${ }^{11}$ were used to select the efficient biosurfactant producer. Bath assay ${ }^{\mathbf{1 2}}$ was performed to estimate bacterial cell surface hydrophobicity using the following equation.

Cell surface hydrophobicity $=100 \times[1-(\mathrm{OD}$ of the aqueous phase/OD of the cell suspension)]

$\mathrm{OD}=$ optical density at $600 \mathrm{~nm}$.

\subsection{Surface tension and rheological property}

The ST of the cell free supernatant was measured by the Du Nouy method using an electronic tensiometer (Data physics DCAT 11, Germany) at $25{ }^{\circ} \mathrm{C}$ taking ST of distilled water as control. Percentage reduction of ST was estimated using the following equation. ${ }^{13}$

Percentage ST reduction $=\left\{\left(\gamma_{\mathrm{m}}-\gamma_{\mathrm{c}}\right) / \gamma_{\mathrm{m}}\right\} \times 100$
Where $\gamma_{m}$ and $\gamma_{c}$ were the ST of initial medium and ST of cell free supernatant respectively.

\subsection{Isolation and purification of biosurfactant}

A bacterial suspension $\left(5 \times 10^{5} \mathrm{cfu} \mathrm{m}^{-1}\right)$ in $100 \mathrm{ml}$ sterilized $\mathrm{BH}$ media containing $2 \mathrm{~g}$ FF was placed in shaker. Samples were removed after every $24 \mathrm{~h}$ interval and the ST was measured after centrifugation (7000 rpm for $15 \mathrm{~min}$ ) to determine the minimum time required for maximum ST lowering. The cell free supernatant was acidified by $\mathrm{HCl}$ up to $\mathrm{pH} 2.00$ and kept overnight at $4{ }^{\circ} \mathrm{C}$ which was further centrifuged at $10000 \mathrm{rpm}$ for $15 \mathrm{~min}$ at $4{ }^{\circ} \mathrm{C}$ and the precipitate was dissolved in methanol. Finally, methanol was evaporated in rotary evaporator (Eyela, Rikakikai Co. Ltd., Tokyo, Japan) at $40{ }^{\circ} \mathrm{C}$ under reduced pressure.

\subsection{Estimation of critical micelle concentration (CMC)}

CMC of the crude biosurfactant was examined by preparing a series of solution of biosurfactant from $1 \mathrm{mg} \mathrm{l}^{-1}$ to $200 \mathrm{mg} \mathrm{l}^{-1}$ in deionized water and the ST was estimated.

\subsection{Chemical characterization of the biosurfactant by FT-IR, ${ }^{1} \mathrm{H}$ NMR and mass spectrometric analysis}

The IR spectra of the biosurfactant were recorded on FTIRspectrophotometer (Jasco, FT/IR-6300, USA) in 4000-400 $\mathrm{cm}^{-1}$ region at a resolution of $2 \mathrm{~cm}^{-1}$ using a $\mathrm{KBr}$ pellet. The pellet was prepared by grinding biosurfactant and dry $\mathrm{KBr}$ in $1: 9$ ratio followed by pressing under $7500 \mathrm{~kg}$ weight for $30 \mathrm{~s}$ to attain a translucent pellet.

Proton nuclear magnetic resonance $\left({ }^{1} \mathrm{H}\right.$ NMR) of the purified biosurfactant was recorded on Bruker Avance $400 \mathrm{MHz}$ spectrometer using tetramethyl silane (TMS) as internal standard and deuterated water as solvent.

Mass spectrometric analysis of purified biosurfactant was performed on JEOL MS station (JMS-700) after dissolving in deionized water.

\subsection{Stability study in different conditions}

Stability of the biosurfactant was performed under wide range of temperature, $\mathrm{pH}$ and salinity at its CMC. Thermal stability was checked by keeping it at $100{ }^{\circ} \mathrm{C}$ for different time periods $(0,5,10,20,40$ and $60 \mathrm{~min})$ and autoclaving at $121{ }^{\circ} \mathrm{C}$ for 15 min. Stability at $\mathrm{pH}$ values (2 to 13 ) of the biosurfactant was examined. Effect of salinity on the stability of surfactant property was examined by treating it with different concentrations of $\mathrm{NaCl}(0-6 \% \mathrm{w} / \mathrm{v})$ and the ST was examined after keeping it for 5 days at room temperature. ${ }^{\mathbf{1 4}}$

\subsection{Evaluation of in vitro antioxidant activity}

2.9.1 DPPH-radical scavenging assay. The DPPH free radical scavenging potential of the test biosurfactant, BS15 at different concentrations (1-5 $\mathrm{mg} \mathrm{ml}^{-1}$ ) was estimated as described by Bersuder P. et al. ${ }^{15}$ The radical-scavenging activity was expressed as the inhibition percentage of DPPH radical taking ascorbic acid as the standard following the equation. 
Inhibition of DPPH radical (\%)

$$
=\frac{\text { Abs control }- \text { Abs sample }}{\text { Abs control }} \times 100
$$

Where, Abs control was the absorbance of the control reaction and Abs sample was the absorbance of the test biosurfactant. Ascorbic acid was used as the standard. The concentration of sample at which DPPH radicals were scavenged by $50 \%$ was taken as the $\mathrm{IC}_{50}$.

2.9.2 Hydrogen peroxide scavenging activity. The hydrogen peroxide scavenging activity of different concentration of biosurfactant, BS15 was determined according to the method of Ruch R. J. et al. ${ }^{\mathbf{1 6}}$ taking ascorbic acid as the standard with the help of the following equation.

$$
\begin{array}{r}
\% \text { scavenged } \mathrm{H}_{2} \mathrm{O}_{2}=[(1-\text { absorbance of control/ } \\
\text { absorbance of sample }) \times 100]
\end{array}
$$

\subsection{Determination of antimicrobial activity}

The antimicrobial activity of the produced biosurfactant was found against a common Gram positive bacterium, Staphylococcus aureus ATCC 25923 and a Gram negative bacterium, Escherichia coli ATCC 8739 collected from Institute of microbial technology, Chandigarh, India. The antimicrobial activity and minimum inhibitory concentration (MIC) were determined by broth dilution technique as per the guideline of European Committee for Antimicrobial Susceptibility Testing (EUCAST) of the European Society of Clinical Microbiology and Infectious Disease (ESCMID). ${ }^{17}$ A broth without drug was regarded as negative control and ciprofloxacin as positive control.

\subsection{Wound healing activity}

Keeping in view the antioxidant and antimicrobial activity of the biosurfactant BS15, an endeavour was taken to investigate its potential for excisional wound healing after preparing water based ointment with it.

2.11.1 Preparation of ointment. To prepare a hydrophilic ointment, $25 \mathrm{~g}$ stearyl alcohol and $25 \mathrm{~g}$ white petrolatum were melted, which was slowly added to a heated aqueous solution containing $475 \mathrm{mg}$ lyophilized BS15, $1 \mathrm{~g}$ sodium lauryl sulphate and $12 \mathrm{~g}$ propylene glycol dissolved in $37 \mathrm{ml}$ distilled water. Concentration of BS15 in final formulation was maintained as $5 \mathrm{mg} \mathrm{ml}{ }^{-1} \cdot{ }^{18}$ Similar method was followed without adding biosurfactant to form an ointment base for treating control group.

2.11.2 Skin irritation test. The animals used for this study were six adult male rabbit (supplied by local supplier of registration no. 1443/PO/b/11/CPCSEA) of weighing 1.2 to $2.5 \mathrm{~kg}$. The animals were acclimatized under laboratory condition at $25 \pm$ $1{ }^{\circ} \mathrm{C}$ and $55 \pm 5 \%$ relative humidity with $12: 12 \mathrm{~h}$ light and dark circle. Standard laboratory diet and water were provided ad libitum. The experimental protocol followed in this study was described by Pople P. V. et al. ${ }^{19}$ The dorsal part of each rabbit was shaved prior to the experiment and divided in four marked areas for topical application. The marked areas were treated with test biosurfactant ointment, ointment base as control, 10\% $\mathrm{w} / \mathrm{v}$ formalin solution as positive control and framycetin sulphate ointment (Sanofi India Ltd., Mfg. Lic. no. 439/L, Batch no. E6363, Mfg. date-10/2016; Exp. date-03/2019) as standard drug. A careful observation was followed up to $24 \mathrm{~h}$ to notice any erythema and edema as indication of irritation.

2.11.3 Excision wound healing model. Young male wister rats of $150 \mathrm{~g}$ to $200 \mathrm{~g}$ body weight were used for the experiment which was supplied by a local supplier (Registration no. 1443/ $\mathrm{PO} / \mathrm{b} / 11 / \mathrm{CPCSEA})$. The animals were acclimatized at $26{ }^{\circ} \mathrm{C} \pm$ $2{ }^{\circ} \mathrm{C}$ in $12 \mathrm{~h}$ light/dark cycle and $60-70 \%$ relative humidity condition for 7 days before the experiment. The animals were allowed free access to standard food pellets and water ad libitum. The animal experiment was executed following OECD Guidelines and Gaitonde Committee Guidelines which was approved by Institutional Animal Ethics Committee (Registration no. 1180/ac/08/CPCSEA).

2.11.4 Study design. Twenty-four hours before the experiment, the dorsal skin of rats $(n=6)$ was shaved. Before the experiment, each rat was anaesthetized with i.p. injection of thiopentone sodium at a dose of $35 \mathrm{mg} \mathrm{kg}^{-1}$. Punch wounds of $8 \mathrm{~mm}$ diameter were inflicted on the back side of each anaesthetized rat with the help of a sterile circular blade, ${ }^{20}$ Acu-Punch (Acuderm Inc., FL, USA). The prepared ointment was administered topically at a dose of $2.5 \mathrm{mg} \mathrm{kg}^{-1}$ twice a day till the complete healing.

Group I: untreated (negative control) group (NC).

Group II: ointment base treated control group (OB).

Group III: BS15 (5 $\mathrm{mg} \mathrm{ml}^{-1}$ dose) treated group (BS).

Group IV: framycetin sulphate ointment treated group (FS).

The medications were administered topically to cover the wound completely. Treatment was continued for 10 days at a fixed time, each day.

2.11.5 Measurement of wound closure and wound index. The zone of wound closure of individual animal was estimated in $\mathrm{mm}^{2}$ by tracing the wound using a transparent graph paper and a marker on day 0, 5, 7 and 10 respectively. ${ }^{21,22}$ The reduction of wound area was expressed as percentage wound contraction using the following formula.

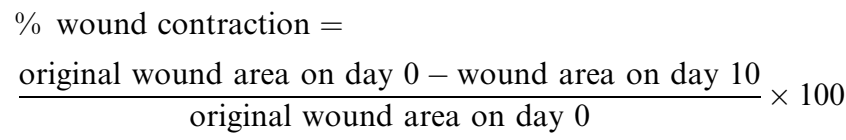

Wound index was calculated following an arbitrary scoring system $^{20}$ as mentioned in Table 1 .

2.11.6 Determination of tensile strength. The tensile strength ${ }^{23}$ of healed wound signified collagenesis at the wound site. The force required to open the regenerated tissue indicated extent of healing. Tensile strength was estimated by tensiometer (M/S Excel Enterprises, Kolkata, India) after 10 days treatment.

2.11.7 Estimation of biochemical parameters. An Acupunch needle of $8 \mathrm{~mm}$ diameter was used to cut the regenerated tissue for estimation of total protein, DNA and hexosamine. The collected tissue was homogenised in 10\% TCA, 
Table 1 Arbitrary scoring system for the measurement of wound index

\begin{tabular}{ll}
\hline Gross change & Wound index \\
\hline Complete healing of wound & 0 \\
Incomplete but healthy healing of wound & 1 \\
Delayed but healing & 2 \\
No instigation of healing but the environment & 3 \\
is healthy & \\
Pus formation: proof of necrosis & 4 \\
Total & 10
\end{tabular}

centrifuged and treated with $0.1(\mathrm{M}) \mathrm{NaOH}$ solution. Protein content was estimated by Lowry method $^{24}$ from the upper supernatant part and DNA content was measured from the yield precipitate by Burton's method. ${ }^{25}$

Hexosamine content was measured from approximately $40 \mathrm{mg}$ of dried granulated tissue samples. The tissue was hydrolyzed and hexosamine was estimated following the method described by Dische Z. et al. ${ }^{26}$ using a standard curve of $\mathrm{D}-(+)$-glucosamine hydrochloride.

2.11.8 Determination of TNF- $\alpha$ by ELISA assay. Immunological determination of TNF- $\alpha$ in blood was performed by collecting blood samples from the heart of anaesthetized rats for all the four groups at specified time intervals i.e. 3, 5, 7, and $10^{\text {th }}$ days after creating wound. Collected blood samples from heart were centrifuged at $4000 \mathrm{rpm}$ for $10 \mathrm{~min}$ to separate the serum. The experiment was executed by sandwich ELISA following the rat TNF- $\alpha$ kit (BioLegend, USA) manufacturer guideline.

2.11.9 Histological examination. The regenerated tissue samples from each group was collected on day 10 and preserved immediately in $10 \%$ formalin solution to perform histopathological study after haematoxylin and eosin staining. The extent of healing in terms of re-epithelialisation, maturation, formation of epidermal squamous cells, granular cell layer, matrix organization and scar formation in dermis was observed from the photograph of the section taken under optical microscope (Motic, B1 series, Hong Kong). The results of BS group were compared with NC and FS groups.

\subsection{Statistical analysis}

Statistical data analysis was performed and shown as mean \pm standard error of mean (SEM). The statistical significance was considered using one-way analysis of variance (ANOVA) using GraphPad Prism version 5.01. (California, USA) and were considered significant when $P$ was less than 0.05 . All the experiment was performed thrice.

\section{Results and discussion}

\subsection{Isolation and identification of the organism}

After screening from a large number of isolates an effective biosurfactant producer (A15) was selected on the basis of ST lowering capability. The cell free supernatant showed highest reduction of ST from $71.02 \mathrm{mN} \mathrm{m}^{-1}$ to $32.2 \mathrm{mN} \mathrm{m}^{-1}$ i.e. $54.64 \%$ as compared to other isolates.

As per the biochemical results the selected strain was an aerobic, rod shaped, endospore forming Gram positive bacteria and the colonies were of irregular shaped. It expressed positive response for catalase activity and negative for oxidase activity. Though the strain could not produce amylase but it produced protease as examined by hydrolysis of skim milk. All these properties indicated the test strain as a member of Bacillus genus. In addition to the biochemical tests 16S rRNA gene sequence (1441 bp) analysis shown $97.8 \%$ homology with Bacillus stratosphericus $41 \mathrm{KF} 2 \mathrm{a}(\mathrm{T})$. The phylogenetic tree constructed with 16S rRNA gene sequence as presented in Fig. S1. $\dagger$ The NCBI GeneBank accession number of the test bacteria was KU644139 and it should be classified as a strain of Bacillus sp. A15. Bacillus stratosphericus has been reported to produce extracellular alkaline protease. ${ }^{27}$ But our study focused on biosurfactant production of Bacillus stratosphericus using Catla catla $\mathrm{FF}$.

\subsection{Screening of biosurfactant producer}

3.2.1 Blood haemolysis, cell surface hydrophobicity and oil displacement test. The isolated bacterial strain exhibited haemolytic activity by showing clear zone (Fig. S2 $\dagger$ ) around the colony on blood agar plate. The Bacillus strain showed positive response for BATH assay. The cell surface hydrophobicity towards hexadecane was calculated as $67.21 \pm 2.87 \%$. Significant result of positive drop collapse test by the organism was found to be $2.87 \pm 0.24 \mathrm{~cm}$ diameter compared to control $(1.42 \pm 0.29 \mathrm{~cm})$. Haemolytic activity, cell surface hydrophobicity and oil displacement test are widely used as screening methods for biosurfactant producer. ${ }^{28-30}$

3.2.2 Surface activity and rheological measurements. The produced BS reduced the ST of distilled water from $71 \pm 0.5 \mathrm{mN}$ $\mathrm{m}^{-1}$ to $33.2 \mathrm{mN} \mathrm{m}^{-1}$ i.e. $53.24 \%$ of its initial.

\subsection{Kinetics of biosurfactant production}

After $48 \mathrm{~h}$ of growth, the lowering of ST started which continued till $120 \mathrm{~h}$ (lowest value of $32.2 \mathrm{mN} \mathrm{m}^{-1}$ ) along with a similar profile of increase in biomass. Thus it indicated that the biosurfactant production from Catla catla $\mathrm{FF}$ occurred in the exponential growth phase of the Bacillus sp. and it followed growth associated kinetics ${ }^{31}$ (Fig. 1).

\subsection{Critical micelle concentration}

The curve for showing CMC of the biosurfactant (Fig. S3†) derived from A15 strain expressed a CMC value of $46.8 \mathrm{mg} \mathrm{l}^{-1}$ at $25{ }^{\circ} \mathrm{C}$.

Efficient surfactants show very low CMC value. The CMC value of BS15 was significantly lower than similar lipopeptide type biosurfactants as reported by others. ${ }^{32,33}$ The fatty acid part of lipopeptide plays an important role in controlling its surface active properties and the number of carbon atom in fatty acid chain is inversely related to the CMC. ${ }^{34,35}$ 


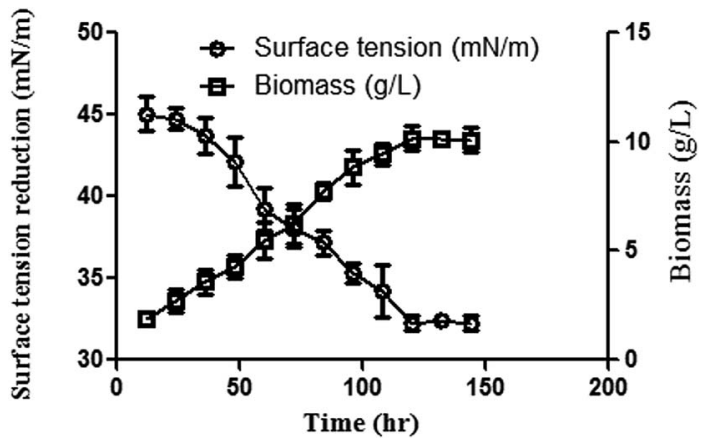

Fig. 1 Increase in biomass and ST reduction profiles of Bacillus sp. mean \pm SEM of three individual experiments.

\subsection{Characterization of BS15}

3.5.1 FT-IR spectrum of purified BS15. The FT-IR spectra played an important role to identify the presence of functional groups present in BS15. The FTIR spectrum (Fig. 2) illustrated characteristic peptide linkage by showing band at $3291 \mathrm{~cm}^{-1}$ (NH stretching mode) and $1657 \mathrm{~cm}^{-1}$ (stretching mode of CO-N bond). ${ }^{36}$ The band at $1542 \mathrm{~cm}^{-1}$ also indicated the presence of peptide by showing deformation mode of $\mathrm{N}-\mathrm{H}$ bond combined with C-N stretching mode. ${ }^{37}$ The bands from $2957 \mathrm{~cm}^{-1}$ to 2855 $\mathrm{cm}^{-1}$ and $1451 \mathrm{~cm}^{-1}$ to $1383 \mathrm{~cm}^{-1}$ implied the presence of aliphatic chains (C-H stretching mode). ${ }^{38}$ The IR band at 1723 $\mathrm{cm}^{-1}$ indicated the presence of ester carbonyl group. ${ }^{39}$ All these FT-IR profiles indicated that the isolated biosurfactant contained aliphatic chain in combination with peptide linkage. These results indicated a similarity in structure of the isolated biosurfactant, BS15 with the IR spectra of previously reported lipopeptide-surfactin. ${ }^{36}$ Lipopeptide is one of the important types of biosurfactant produced by Bacillus sp. ${ }^{40}$

3.5.2 ${ }^{1} \mathbf{H}$ NMR analysis. The results of proton NMR spectroscopy of BS15 (Fig. 3) at $400 \mathrm{MHz}$ indicated the presence of amide (-CO-NH) functional group by showing signal at $\delta 5.36 \mathrm{ppm}$. The isolated biosurfactant contained a long aliphatic chain $\left(\mathrm{CH}_{2}\right.$ at $\left.\delta 1.47-1.18 \mathrm{ppm}\right)$ with $\alpha$ carbon $(\delta 3.52-$ $5.30 \mathrm{ppm}$ ) and side chain protons (0.75-2.73 ppm). The NMR

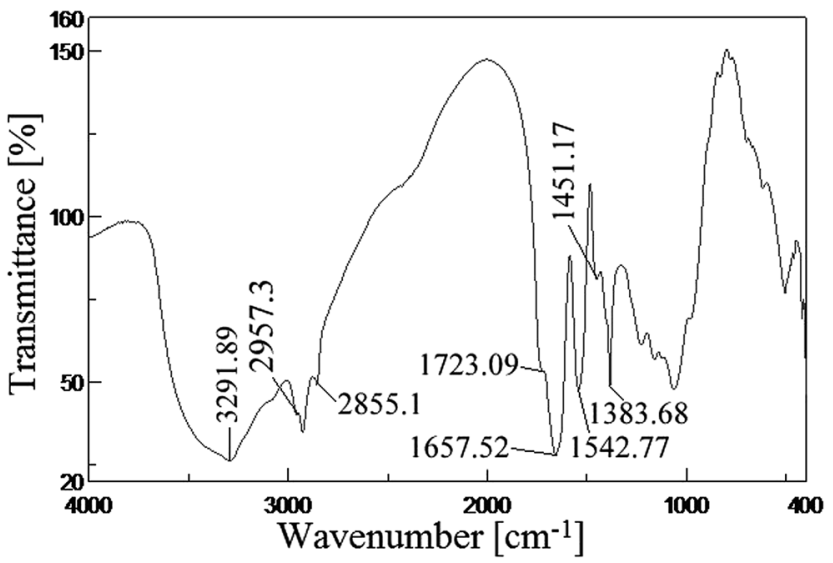

Fig. 2 FTIR absorption spectra of BS15 produced by Bacillus stratosphericus A15 from Catla catla fish fat. spectrum at $5.22 \mathrm{ppm}$ signified the presence of ester carbonyl group may be due to existence of lactone ring in the structure of BS15. ${ }^{41}$ The chemical shift $\delta$ at $5.12 \mathrm{ppm}$ suggested the attachment of an amino acid residue to the C-3 of hydroxyl fatty acid (3HFA) by ester bond. The spectrum at $\delta 3.66 \mathrm{ppm}$ suggested the presence of $-\mathrm{OCH}_{3}$ in the isolated molecule which was supported by previous reports showing methoxy group in amino acid part of Glu or Asp. The existence of methyl ester formation in the molecular structure of BS15 can increase the hydrophobicity and thereby improve the ST lowering capacity, antifungal activity and haemolytic property. ${ }^{42}$ All the resonance showed similarity of BS15 with Bacillus sp. derived surfactin type biosurfactant.

3.5.3 Mass spectrometry. The mass spectrometric analysis (Fig. 4) of BS15 ( $\mathrm{m} / \mathrm{z} 794)$ was compared with previous reports. The mass spectra of the dissociated ions showed peaks at $\mathrm{m} / \mathrm{z}$ 794, 695, 589, 486, 373 and 233 that signified the sequential losses of amino acid residues Val/Asp/Val/Leu/Leu/GluOMe present in BS15 produced by Bacillus stratosphericus A15 which is nearly similar to previous report of surfactin. ${ }^{37}$ The fragmentation residue from $\mathrm{m} / \mathrm{z} 373$ to $\mathrm{m} / \mathrm{z} 233$ showed the loss of 140 Da due to presence of methylated glutamic acid (GluOMe) which confirmed the existence of methyl esterified amino acid residue. The BS15 displayed $[\mathbf{M}+\mathbf{H}]^{+}$ion of $m / z 233$, which corresponded to the amino acid moiety linked to aliphatic carbon chain containing 14 carbons in normal, iso or anteiso configuration. This ionic profile indicated that the isolated molecule contained cyclic 6 membered peptide linked to $\beta$ hydroxy fatty acid chain having 14 carbons. The calculated molar ratio of present amino acids i.e. Glu : Asp : Val : Leu was $1: 1: 2: 2$ respectively. Still the result of dissociation was not able to differentiate Ile from Leu as these are isomeric in nature. Nearly similar type of C12 lipopeptide containing Asp, Glu, Val and Leu in molar ratio of $1: 1: 1: 4$ was produced by Bacillus subtilis HSO according to the report of Liu X. Y. et al. ${ }^{43}$ Apart from few differences, the isolated lipopeptide type biosurfactant produced by Bacillus stratosphericus A15 showed many similarities with previously reported structure of surfactin. ${ }^{37}$

\subsection{Stability study}

The application of biosurfactant depends on its stability (Fig. 5) at extreme conditions of thermal treatment, $\mathrm{pH}$ and salinity. The Bacillus sp. derived biosurfactant showed to be thermostable by exhibiting stability up to $100{ }^{\circ} \mathrm{C}$ for $60 \mathrm{~min}$ and also autoclaving without changing the surface active property. It also showed stability over a $\mathrm{pH}$ range of 4 to 12 with maximum stability at alkaline $\mathrm{pH} 8$ which might signify a better stability of fatty acid surfactant micelles in the presence of alkali. The solution turned turbid at acidic $\mathrm{pH}$ due to partial precipitation. The biosurfactant derived from the Bacillus sp. was also found to be stable within a wide range of $\mathrm{NaCl}$ concentration. Hence BS15 can be safely applied in food, pharmaceutical, cosmetic, petroleum and ore handling industries.

\subsection{Antioxidant activity of the biosurfactant}

3.7.1 DPPH radical scavenging activity. The free radical scavenging activity of BS15 in varying concentrations was tested 


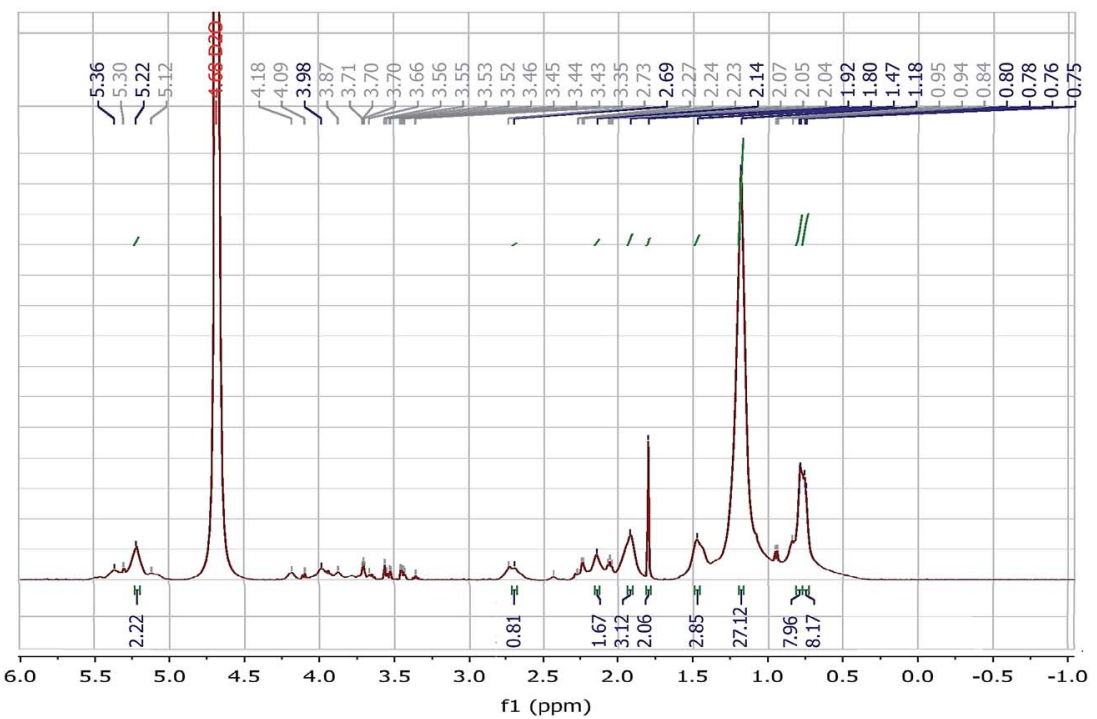

Fig. $3{ }^{1} \mathrm{H}$ NMR spectra of BS15.

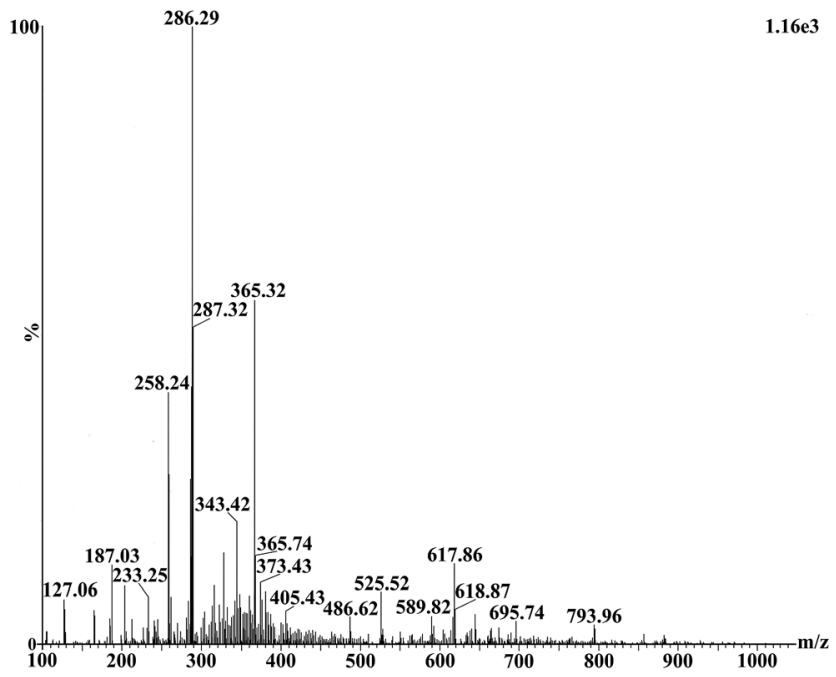

Fig. 4 Mass spectrum of isolated BS15 from Bacillus stratosphericus A15.

with DPPH, comparing ascorbic acid as standard. BS15 (Fig. 6) expressed a concentration dependant scavenging activity by showing potential effect $(15 \%)$ at $35 \mu \mathrm{g} \mathrm{ml} \mathrm{m}^{-1}$, which was comparable to that of ascorbic acid (21\%) at the same concentration. The produced BS15 expressed a satisfactory IC $_{50}$ value of $82.4 \mu \mathrm{g} \mathrm{ml}^{-1}$. Reports are available on similar scavenging activity of lipopeptide produced by other strains of Bacillus subtilis. ${ }^{\mathbf{4 4 , 4 5}}$

3.7.2 Hydrogen peroxide radical scavenging assay. Hydrogen peroxide radical scavenging activity is considered to be a good model for estimating the prevention of oxidative stress by hydroxyl radical. The BS15 molecule might stabilize the radical by providing electrons in a concentration dependant manner producing water as shown in Fig. 7. At $150 \mu \mathrm{g} \mathrm{ml}^{-1}$ and $200 \mu \mathrm{g} \mathrm{ml}{ }^{-1}$, the scavenging effect of BS15 expressed similar efficacy $(12 \%$ and $13 \%)$ to ascorbic acid (14\% and $16 \%)$ with $\mathrm{IC}_{50}$ of $845.37 \mu \mathrm{g} \mathrm{ml} \mathrm{g}^{-1}$ in case of BS15 and $638.8 \mu \mathrm{g} \mathrm{ml} \mathrm{m}^{-1}$ for ascorbic acid respectively.

BS15 could donate hydrogen to free radicals, particularly to the lipid peroxides or hydrogen peroxide radicals, the major propagators of the chain autoxidation of lipids, to form non-radical species, resulting in the inhibition of lipid peroxidation. $^{46}$ Thus BS15 might act as a potential wound healing agent by preventing oxidative damage at the wound site.
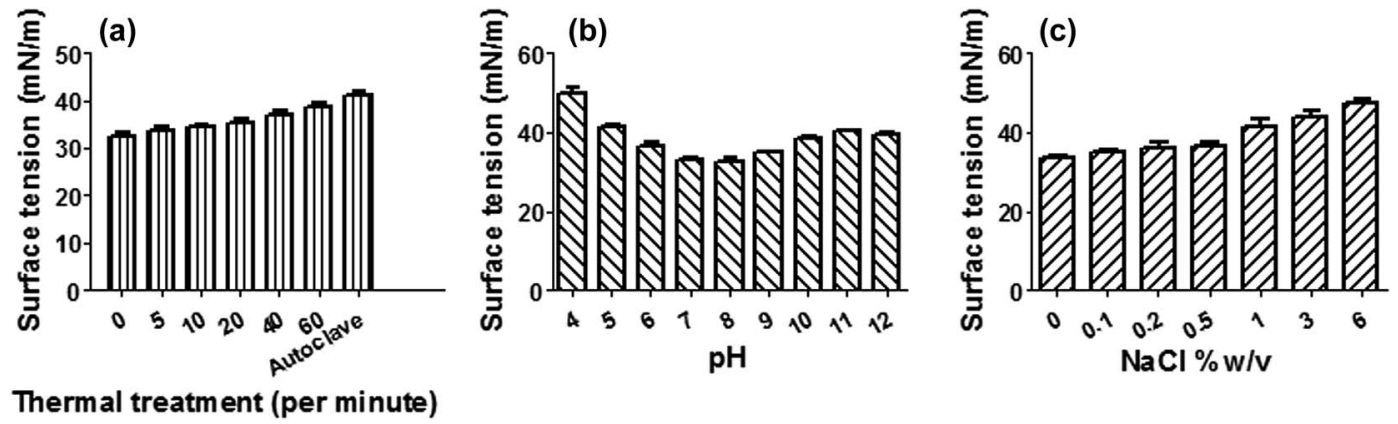

Fig. 5 Effect of (a) temperature, (b) $\mathrm{pH}$ and (c) salinity on the stability of biosurfactant. 


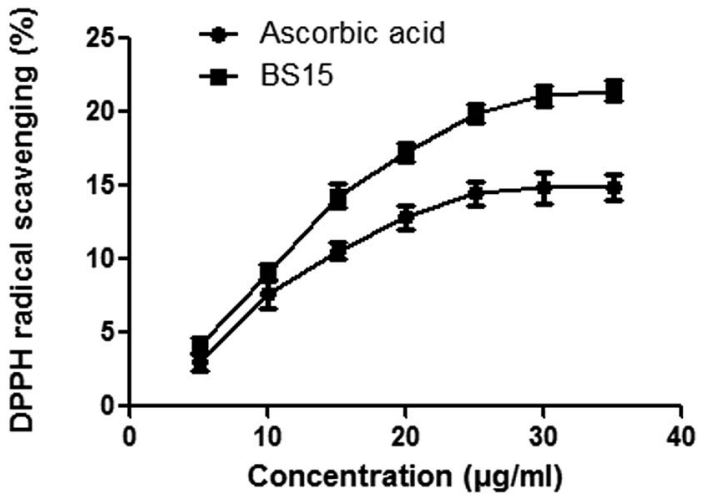

Fig. 6 DPPH radical scavenging activity of BS15 at different concentrations.

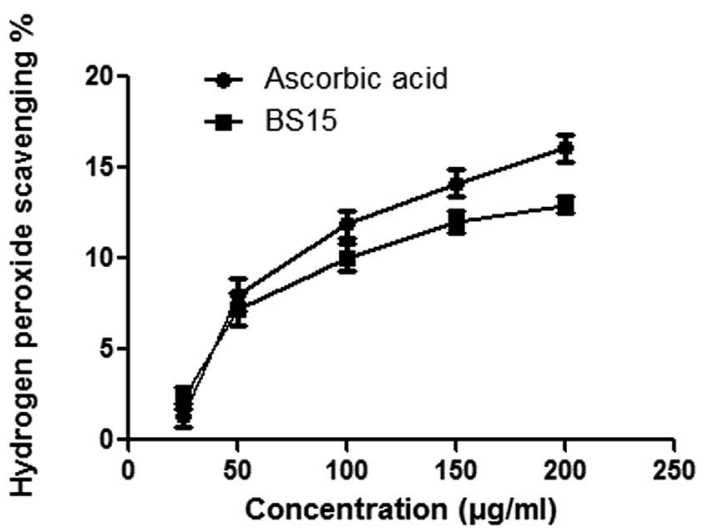

Fig. $7 \quad \mathrm{H}_{2} \mathrm{O}_{2}$ scavenging activity of $\mathrm{BS}$ at different concentrations.

\subsection{Antimicrobial activity}

Lipopeptide biosurfactants like surfactin, iturin, lichenysin can act as effective antibacterial agent against a wide range of Gram positive and Gram negative bacteria in comparison to other classes of biosurfactants. ${ }^{47}$ The isolated biosurfactant showed MIC value of $600 \mu \mathrm{g} \mathrm{ml} \mathrm{m}^{-1}$ and $100 \mu \mathrm{g} \mathrm{ml} \mathrm{m}^{-1}$ against Staphylococcus aureus ATCC 25923 and Escherichia coli ATCC 8739 respectively. This antimicrobial activity of the isolated biosurfactant may help in faster healing by preventing bacterial infection at the wound site.

\subsection{Skin irritation}

The BS15 ointment was free from skin irritation by showing no sign of erythema and edema following $24 \mathrm{~h}$ dermal exposure when applied to rabbit skin.

\subsection{Wound healing activity of BS15}

3.10.1 Wound closure and evaluation of epithelialisation. Main target of any wound healing study was to close the wound as early as possible. Wound healing of BS15 was visually expressed by wound closure, percentage wound contraction, wound index and tensile strength of regenerated tissue.
The visual observation (Fig. 8) revealed the progress of healing of NC, OB, BS and FS groups respectively. The rate of healing was significantly higher $(P<0.05)$ in BS and FS groups in comparison to other two groups in terms of wound closure. No significant changes were observed on first 2 days of treatment for all the groups.

From day 3 the wound turned dark red in colour which indicated the beginning of healing. The number of new blood vessels and the depth of dermal tissues at the wound site were significantly increased in BS and FS groups from the $5^{\text {th }}$ day of treatment. Also swelling, redness and microbial attack was absent in these groups. Finally, complete wound closure and granulation tissue formation were achieved on $10^{\text {th }}$ day of treatment. Conversely the NC and OB groups were followed by pus formation, microbial attack and the wound remained open till the end of treatment. This finding was supported by literature $^{48}$ as natural contraction of wound occurred in 21 days.

The wound closure was monitored and expressed as in Fig. 8 where the BS group exhibited best wound closure $\left(1.17 \mathrm{~mm}^{2}\right)$ in comparison to NC group $\left(14.17 \mathrm{~mm}^{2}\right)$, OB group $\left(10.67 \mathrm{~mm}^{2}\right)$ and FS group $\left(1.83 \mathrm{~mm}^{2}\right)$ after 10 days treatment.

The percentage wound closure of BS15 group after 10 days treatment established a promising result of $97.70 \%$, which was even better than FS group $(96.43 \%)(P<0.05)$. Whereas at the end of treatment, percentage wound contraction of OB $(79.02 \%)$ group was near to NC $(72.40 \%)$ group but much lower than the BS and FS group. So, significant healing effects in terms of faster wound contraction were observed in BS and FS treated groups in comparison to other groups.

The mean wound indices of each group on $3^{\text {rd }}, 5^{\text {th }}, 7^{\text {th }}$ and $10^{\text {th }}$ days of treatment were estimated. Mean wound index of BS and FS group on $10^{\text {th }}$ day showed a value of 1.17 and 1.00 respectively $(P<0.05)$ in comparison to NC group (3.17). The mean wound index reduction of $\mathrm{OB}$ group (2.33) was also significant $(P<0.05)$ as compared to NC group.

The tensile strength of the regenerated tissue at wound site is expressed in Table 2. The result showed that the tissue tensile strength of BS (409.83 g) and FS (404.67 g) groups were much higher than the other NC (230.5 g) and OB (312.17 g) group. The

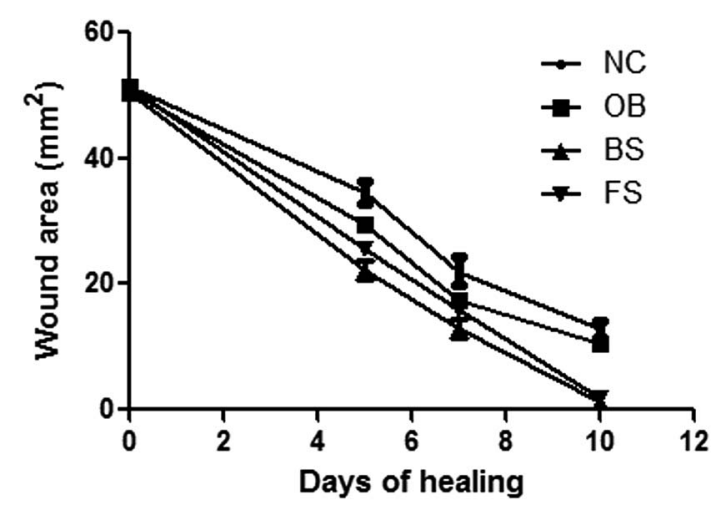

Fig. 8 Area of wound closure $\left(\mathrm{mm}^{2}\right)$ at $0^{\text {th }}, 5^{\text {th }}, 7^{\text {th }}$ and $10^{\text {th }}$ day. Each group contains 6 rats and values are mean \pm SEM. ${ }^{\text {a }} P<0.05$ compared to control group, ${ }^{\mathrm{b}} P>0.05$ compared to BS treated group and ${ }^{\mathrm{C}} P>$ 0.05 compared to FS treated group. 
Table 2 Changes of physiological characteristics of wound in treated groups ${ }^{a}$

\begin{tabular}{|c|c|c|c|}
\hline Treatment groups & $\begin{array}{l}\text { Percentage } \\
\text { wound contraction }\end{array}$ & Wound index & Tensile strength $(\mathrm{g})$ \\
\hline $\mathrm{NC}$ & $72.40 \pm 2.41$ & $3.17 \pm 0.98$ & $230.5 \pm 10.82$ \\
\hline BS15 & $97.70 \pm 1.53^{b, c, d}$ & $1.17 \pm 0.75^{b, c, d}$ & $409.83 \pm 12.56^{b, c, d}$ \\
\hline FS & $96.43 \pm 1.81^{b, c}$ & $1.00 \pm 0.63^{b, c}$ & $404.67 \pm 17.67^{b, c}$ \\
\hline
\end{tabular}

tissue tensile strength and stability increases with collagen maturation by the help of enhancing intramolecular and intermolecular cross linking. ${ }^{49}$

3.10.2 Estimation of biochemical parameter. The increasing protein and DNA content of regenerated tissue at the healed area expressed the beginning of healing process. The protein and DNA content were increased by $37.8 \%$ and $58.7 \%(P$ $<0.05$ ) respectively, in biosurfactant (BS15) treated group compared to control group (NC). The result (Table 3) was nearly similar like FS group as the increment of protein and DNA content of FS group were $37.8 \%$ and $55.0 \%$ respectively.

Hexosamine is one of the components of glycosaminoglycan family. It is the prime element for synthesis of new extracellular matrix. ${ }^{50}$ The glycosaminoglycan improves electrostatic and ionic interaction to alleviate the collagen fibres and its characteristic size. Table 3 clearly expressed that BS15 (47.4\%) treatment significantly increased the hexosamine content, compared to control $(P<0.05)$ at the end of 10 days treatment, thereby it helped in the progress of wound healing in terms of collagen content regeneration and stabilization of collagen fibres. FS (46.8\%) treatment also expressed similar type result.

3.10.3 Determination of TNF- $\alpha$ in blood serum. The TNF$\alpha$ level of serum of all groups were estimated which were collected at an interval of 3, 5, 7 and 10 days after creating wound. The change of proinflammatory cytokine TNF- $\alpha$ level in blood serum showed (Fig. 9) that lowering of TNF- $\alpha$ was much more significant $(P<0.05)$ in the BS and FS treated groups compared to other two groups. It was noticed that the TNF$\alpha$ level of the four groups i.e. NC, OB, BS and FS were primarily increased up to $5^{\text {th }}$ day of treatment and after that it was decreased slowly till the end of treatment period. The changing behaviour of TNF- $\alpha$ signified healing effect of BS15 which was supported by other reports as they explained that TNF- $\alpha$ level in serum increased at the initial phase of inflammatory stage and followed by reduction up to normal level along with the treatment of wound. ${ }^{51}$ Various stages of healing involves several cell types like growth factors, cytokines and extracellular matrix (ECM) constituents. Matrix metalloproteinases (MMPs) are engaged in healing process through matrix re-modeling and angiogenesis. The secretion of active MMP2 is mediated by activation of TNF- $\alpha$ through pro-MMP-2.52 Thus the lowering level of TNF- $\alpha$ at the end of treatment period strongly signified the well organised healing effect of BS15.

3.10.4 Histology of regenerated tissues. Hematoxylin and eosin stained sections of granulated tissues after 10 days treatment exhibited a promising healing effect of test BS in terms of tissue regenerating efficacy (Fig. 10) with respect to other groups. The histological pictures of granulated tissue of NC (Fig. 10a) and OB (Fig. 10b) group expressed incomplete regeneration process by showing maximum number of immature fibroblasts at the dermis region and lack of hair follicles or vacuoles. Existence of empty spaces in the dermal region of OB group signified edema. In fact, the histology of NC group expressed that their wound still had not been completely healed.

The histological examination of BS (Fig. 10c) and FS (Fig. 10d) groups showed similarity of healing by expressing well organized granular tissue reepithelialisation, satisfactory formation of thick layered keratinocyte and wide epidermal layer with clear periphery between dermal and epidermal region. The presence of hair follicles, sebaceous glands and higher number of intact cells in dermis layer at the end of scheduled treatment period showed well organised regeneration process. The dermis papillae were also apparently perceived. The topical application of BS15 significantly minimized the wound closure time with potent healing effect on full thickness excision wound. Among the various sequential stages of wound healing, proliferation and migration of epithelial cells are the most important phase for healing. ${ }^{53}$ Topical application of BS15 markedly enhanced the in vivo excision wound by both

Table 3 Changes of biochemical parameters of wound tissues in treated groups ${ }^{a}$

\begin{tabular}{llll}
\hline $\begin{array}{l}\text { Treatment } \\
\text { groups }\end{array}$ & $\begin{array}{l}\text { DNA } \\
(\mathrm{mg} \text { per g tissue) }\end{array}$ & $\begin{array}{l}\text { Total protein } \\
(\mathrm{mg} \text { per g tissue) }\end{array}$ & $\begin{array}{l}\text { Hexosamine } \\
(\mu \mathrm{g} \text { per mg tissue) }\end{array}$ \\
\hline NC & $1.135 \pm 0.04$ & $14.98 \pm 0.63$ & $0.296 \pm 0.033$ \\
OB & $1.235 \pm 0.14^{b}$ & $16.87 \pm 0.55^{b}$ & $0.336 \pm 0.022$ \\
BS15 & $1.80 \pm 0.21^{b, c, d}$ & $20.66 \pm 1.68^{b, c, d}$ & $0.437 \pm 0.023$ \\
FS & $1.76 \pm 0.17^{b, c}$ & $20.66 \pm 2.00^{b, c}$ & $0.436 \pm 0.013$
\end{tabular}

${ }^{a}$ Values were mean $\pm \mathrm{SEM}, n=6$ in each group. ${ }^{b} p<0.05$ compared to NC group. ${ }^{c} p<0.05$ compared to OB group. ${ }^{d} p<0.05$ compared to FS group. 


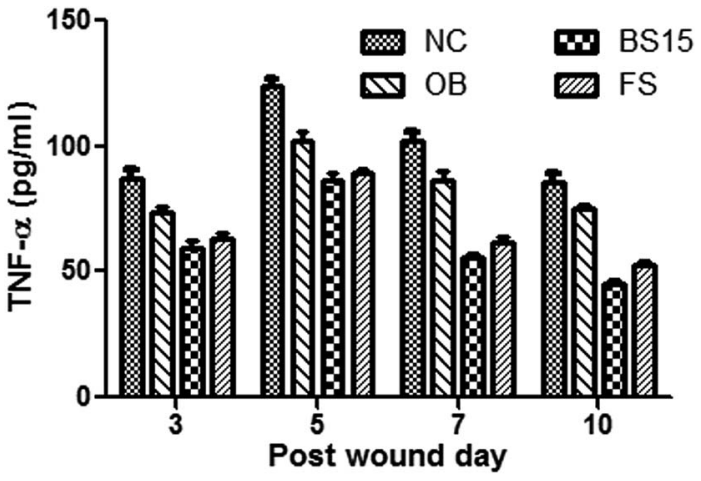

Fig. 9 TNF- $\alpha$ level at different time interval of wound healing by ELISA method (mean $\pm \mathrm{SEM}, n=5, P<0.05$ as compared with the control group).

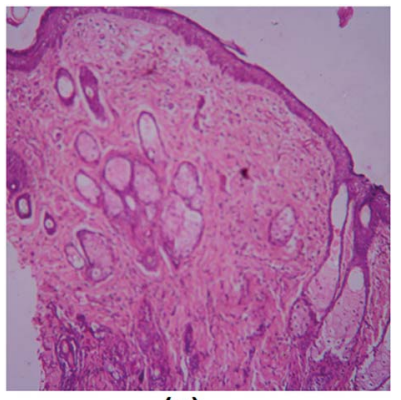

(a)

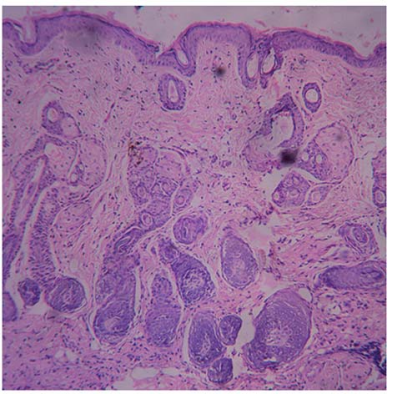

(c)

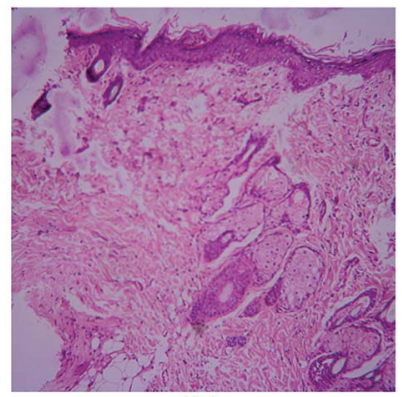

(b)

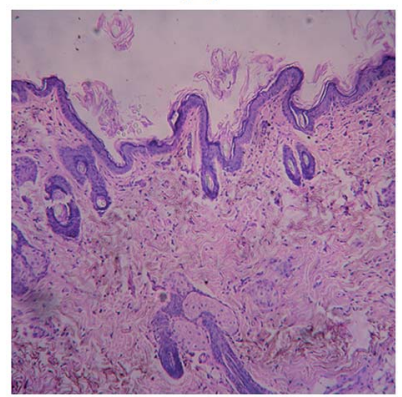

(d)
Fig. 10 Histopathology of granulation tissue after 10 days (a) NC group, (b) OB group showing epidermis formation but lack of hair follicles and sebaceous glands, (c) FS treated group and (d) BS treated group showing well organized granulation tissue and epithelialisation.

migration and proliferation of keratinocytes to cover the wound space and re-epithelialization by newly formed tissue cells at wound site. Contraction of myofibroblasts in granular tissue played advantageous role towards healing process. ${ }^{54}$ The excellent formation of scar tissue with systematically arranged collagen fibres contributed towards healing process by BS and FS.

BS15 lipopeptide thus found to exhibit significant improvement of scar quality both by recovery of organised collagen regeneration and maturation. Lipoprotein expressed wound healing activity by its anti-inflammatory and immunomodulatory effect ${ }^{55}$ which was supported by decrement of TNF- $\alpha$ level in blood serum. It has been shown that TNF- $\alpha$ influenced the inflammatory response, angiogenesis, reepithelialization, extracellular matrix deposition and remodelling. ${ }^{56-58}$ The healing effect of our study can be illustrated by enhancement of granulation tissue formation through increment of endothelial progenitor cells and its paracrine effect which resulted the acceleration of tissue re-epithelialization at the wound site.

\section{Conclusions}

The Catla catla fish fat was chosen as an interesting and costeffective alternative hydro carbon source for both fat degradation and efficient biosurfactant production. It can serve as an excellent model for waste management by protecting the environment and reutilising the animal fat. The physical parameters related to wound closure and biochemical parameters showed significant wound healing of the biosurfactant, BS15 produced by Bacillus stratosphericus A15. Histological studies established a noticeable healing activity in terms of rapid wound closure by connective tissue regeneration, thick epidermal layer and keratinocyte formation at the wound site. In vitro antimicrobial activity and anti-oxidant activity of BS15 was an additional advantage. Hence BS15 could be established as an alternative to antibiotic for application in near future.

\section{Acknowledgements}

We would like to thank University Grants Commission, India for providing financial support and CRNN - University of Calcutta for providing instrumental facilities.

\section{References}

1 T. Velnar, T. Bailey and V. Smrkolj, J. Int. Med. Res., 2009, 37, 1528-1542.

2 G. S. Sidhu, H. Mani, J. P. Gaddipati, A. K. Singh, P. Seth, K. K. Banaudha, G. K. Patnaik and K. Maheshwari, Wound Repair Regen., 1999, 7, 362-374.

3 H. R. P. Naik, H. S. B. Naik, T. R. R. Naik, H. R. Naika, K. Gouthamchandra, R. Mahmood and B. M. Ahamed, Eur. J. Med. Chem., 2009, 44, 981-989.

4 P. J. Houghton, P. J. Hylands, A. Y. Mensah, A. Hensel and A. M. Deters, J. Ethnopharmacol., 2005, 100, 100-107.

5 A. M. Abdel-Mawgoud, F. Lepine and E. Deziel, Appl. Microbiol. Biotechnol., 2010, 86, 1323-1336.

6 I. M. Banat, R. S. Makkar and S. S. Cameotra, Appl. Microbiol. Biotechnol., 2000, 53, 495-508.

7 L. Rodrigues, I. M. Banat, J. Teixeira and R. Oliveira, J. Antimicrob. Chemother., 2006, 57, 609-618.

8 M. Deshpande and L. Daniels, Bioresour. Technol., 1995, 54, 143-150.

9 L. Qingmei, Y. Hang, W. Jun, G. Guohong, Z. Wei, F. Yonghong, W. Li, Y. Jianming and Y. Zengliang, Plasma Sci. Technol., 2006, 8, 491.

10 G. A. Plaza, I. Zjawiony and I. M. Banat, J. Pet. Sci. Eng., 2006, 50, 71-77.

11 D. K. Jain, D. L. Thompson and H. Lee, J. Microbiol. Methods, 1991, 13, 271-279. 
12 M. Rosenberg, D. Gutnick and E. Rosenberg, FEMS Microbiol. Lett., 1980, 9, 29-33.

13 S. Pansiripat, O. Pornsunthorntawee, R. Rujiravanit, B. Kitiyanan, P. Somboonthanate and S. Chavadej, Biochem. Eng. J., 2010, 49, 185-191.

14 H. Amani, M. M. Muller, C. Syldatk and R. Hausmann, Appl. Biochem. Biotechnol., 2013, 170, 1080-1093.

15 P. Bersuder, M. Hole and G. Smith, J. Am. Oil Chem. Soc., 1998, 75, 181-187.

16 R. J. Ruch, S. J. Cheng and J. E. Klaunig, Carcinogenesis, 1989, 10, 1003-1008.

17 European Committee for Antimicrobial SusceptibilityTesting (EUCAST) of the European Society of Clinical Microbiology and Infectious Diseases (ESCMID). Determination of minimum inhibitory concentrations (MICs) of antibacterial agents by agar dilution, Clin. Microbiol. Infect., 2000, 6, 1-7.

18 L. Lachman, H. A. Liberman and J. L. Kanig, The Theory and Practice of Industrial Pharmacy, Varghese Publishing House, Bombay, 3rd edn, 1987, pp. 534-563.

19 P. V. Pople and K. K. Singh, AAPS PharmSciTech, 2006, 7, E63E69.

20 R. G. Auddy, M. F. Abdullah, S. Das, P. Roy, S. Datta and A. Mukherjee, BioMed Res. Int., 2013, 2013, 1-8.

21 B. T. Kanti, A. Biswajit, P. B. Nitai, B. Subahshree and M. Biswapati, Acta Pharmacol. Sin., 2001, 22, 1113-1116.

22 T. K. Biswas, L. N. Maity and B. Mukherjee, Int. J. Lower Extremity Wounds, 2004, 3, 143-150.

23 O. Ziv-Polat, M. Topaz, T. Brosh and S. Margel, Biomaterials, 2010, 31, 741-747.

24 O. H. Lowry, N. J. Rosebrough, A. L. Farr and R. J. Randall, J. Biol. Chem., 1951, 193, 265-275.

25 K. Burton, Biochem. J., 1956, 62, 315-323.

26 Z. Dische and E. Borenfreund, J. Biol. Chem., 1962, 4, 330334.

27 D. A. Bindu and I. B. Reddy, Biochemistry, 2013, 2, 29-31.

28 T. Varadavenkatesan and V. R. Murty, ISRN Microbiol., 2013, 2013, 1-8.

29 C. Mulligan, D. Cooper and R. Neufeld, J. Ferment. Technol., 1984, 62, 311-314.

30 M. Morikawa, Y. Hirata and T. A. Imanaka, BBA-Mol. Cell Biol. L., 2000, 1488, 211-218.

31 A. Persson, E. Osterberg and M. Dostalek, Appl. Microbiol. Biotechnol., 1988, 29, 1-4.

32 Y. Li, R. Q. Ye and B. Z. Mu, J. Surfactants Deterg., 2009, 12, 31-36.

33 K. V. Pathak and H. Keharia, 3 Biotech, 2014, 4, 41-48.

34 N. H. Youssef, K. E. Duncan and M. J. McInerney, Appl. Environ. Microbiol., 2005, 71, 7690-7695.

35 H. Razafindralambo, P. Thonart and M. Paquot, J. Surfactants Deterg., 2004, 7, 41-46.

36 Y. Al-Wahaibi, S. Joshi, S. Al-Bahry, A. Elshafie, A. Al-Bemani and B. Shibulal, Colloids Surf., B, 2014, 114, 324-333.
37 A. F. de Faria, D. S. Teodoro-Martinez, G. N. de Oliveira Barbosa, B. G. Vaz, I. S. Silva, J. S. Garcia, M. R. Totola, M. N. Eberlin, M. Grossman, O. L. Alves and L. R. Durrant, Process Biochem., 2011, 46, 1951-1957.

38 N. K. Bordoloi and B. K. Konwar, Colloids Surf., B, 2008, 63, 73-82.

39 S. Joshi, C. Bharucha and A. J. Desai, Bioresour. Technol., 2008, 99, 4603-4608.

40 A. A. Bodour, K. P. Drees and R. M. Maier, Appl. Environ. Microbiol., 2003, 69, 3280-3287.

41 X. Y. Liu, S. Z. Yang and B. Z. Mu, Process Biochem., 2009, 44, 1144-1151.

42 M. Kowall, J. Vater, B. Kluge, T. Stein, P. Franke and D. Ziessow, J. Colloid Interface Sci., 1998, 204, 1-8.

43 X. Y. Liu, S. Z. Yang and B. Z. Mu, J. Pept. Sci., 2008, 14, 864875.

44 O. Tabbene, D. Gharbi, I. B. Slimene, S. Elkahoui, M. N. Alfeddy, P. Cosette, M. L. Mangoni, T. Jouenne and F. Limam, Appl. Biochem. Biotechnol., 2012, 168, 2245-2256.

45 E. Yalcin and K. Cavusoglu, Turk. J. Biochem., 2010, 35, 243247.

46 C. W. Bamforth, R. E. Muller and M. D. Walker, J. Am. Soc. Brew. Chem., 1993, 53, 79-88.

47 L. Rodrigues, I. M. Banat, J. Teixeira and R. Oliveira, J. Antimicrob. Chemother., 2006, 57, 609-618.

48 W. T. Lawrence, Clin. Plast. Surg., 1998, 25, 321-340.

49 I. K. Hornstra, S. Birge, B. Starcher, A. J. Bailey, R. P. Mecham and S. D. Sapiro, J. Biol. Chem., 2003, 278, 14387-14393.

50 J. M. Trowbridge and R. L. Gallo, Glycobiology, 2002, 12, 117R-125R.

51 R. P. Samy, M. Kandasamy, P. Gopalakrishnakone, B. G. Stiles, E. G. Rowan, D. Becker, M. K. Shanmugam, G. Sethi and V. T. K. Chow, PLoS One, 2014, 9, e80199.

52 Y. P. Han, T. L. Tuan, H. Wu, M. Hughes and W. L. Garner, J. Cell Sci., 2001, 114, 131-139.

53 M. V. Plikus, D. L. Gay, E. Treffeisen, A. Wang, R. J. Supapannachart and G. Cotsarelis, in Seminars in Cell \& Developmental Biology, Academic press, 2012, vol. 23, pp. 946-953.

54 B. Hinz, J. Invest. Dermatol., 2007, 127, 526-537.

55 S. C. Gordts, I. Muthuramu, R. Amin, F. Jacobs and B. D. Geest, Pharmaceuticals, 2014, 7, 419-432.

56 D. P. Poppas, J. M. Massicotte, R. B. Stewart, A. B. Roberts, A. Atala, A. B. Retik and M. R. Freeman, Lasers Surg. Med., 1996, 19, 360-368.

57 D. R. Edwards, G. Murphy, J. J. Reynolds, S. E. Whitham, A. J. Docherty, P. Angel and J. K. Heath, EMBO J., 1987, 6, 1899.

58 M. F. Cordeiro, A. Mead, R. R. Ali, R. A. Alexander, S. Murray, C. Chen, C. York-Defalco, N. M. Dean, G. S. Schultz and P. T. Khaw, Gene Ther., 2003, 10, 59-71. 